\title{
Konjac glucomannan reverses multi-drug resistance of HepG25-FU cells by suppressing AKT signaling and increasing p53 expression
}

\author{
BIN CHEN $^{1}, \mathrm{XIN} \mathrm{XU}^{1}, \mathrm{KE} \mathrm{ZHENG}^{1}, \mathrm{LING} \mathrm{LIU}^{2}, \mathrm{YIJUN} \mathrm{YU}^{1}$ and $\mathrm{YING} \mathrm{XIN}^{3}$ \\ ${ }^{1}$ Department of Hepatobiliary Surgery, The Affiliated Hospital of Hangzhou Normal University, \\ Hangzhou, Zhejiang 310011; ${ }^{2}$ Department of Hepatopancreatobiliary Surgery, \\ The Affiliated Hangzhou Hospital of Zhejiang University, Hangzhou, Zhejiang 310002; \\ ${ }^{3}$ Thyroid and Breast Surgery Department, Zhejiang Provincial People's Hospital, \\ People's Hospital of Hangzhou Medical College, Hangzhou, Zhejiang 310006, P.R. China
}

Received November 22, 2018; Accepted March 18, 2020

DOI: $10.3892 / \mathrm{ol} .2020 .11790$

\begin{abstract}
The multi-drug resistance (MDR) of cancer cells, including 5-fluorouracil (5-FU) resistance, has been a serious problem for patients with cancer. The present study aimed to investigate the reversal effects of konjac glucomannan on multi-drug resistance of HepG2/5-FU cells. In the present study, MTT assay was used to investigate the effects of 5-FU and konjac glucomannan (KGM) on the viability of HepG2/5-FU cells. Reverse transcription-quantitative PCR and western blotting were performed to determine the effects of 5-FU and KGM on the expression of MDR-associated genes including MDR1 and P-glycoprotein 1 (P-gp 1), and to analyze the effects of 5-FU and KGM on the levels of cell proliferation-related genes, including cyclin A, cyclin B1 and CDK2, and apoptosis-related genes, including caspase-3, Bax and BCL-2. Annexin V/propidium iodide staining was performed to determine the apoptotic rate of HepG2/5-FU. Furthermore, the xenograft tumor model was established in nude mice to investigate the in vivo tumor growth by detecting tumor size, volume and tumor weight. KGM significantly decreased the viability of HepG2/5-FU cells in the presence of 5-FU. KGM downregulated the mRNA and protein expression of MDR and P-gp, and inhibited the mRNA and protein expression of cyclin A, cyclin B1 and CDK2. In addition, KGM significantly suppressed BCL-2 expression and increased the expression of cleaved caspase- 3 and Bax, resulting in a higher apoptotic rate of HepG2/5-FU cells. Furthermore, KGM suppressed AKT
\end{abstract}

Correspondence to: Dr Ying Xin, Thyroid and Breast Surgery Department, Zhejiang Provincial People's Hospital, People's Hospital of Hangzhou Medical College, 158 Shangtang Road, Xiacheng, Hangzhou, Zhejiang 310006, P.R. China

E-mail: xinying20012001@163.com

Key words: multi-drug resistance, Konjac glucomannan, HepG2/5-FU, apoptosis, AKT phosphorylation and upregulated p53 expression. Notably, KGM significantly inhibited the growth of HepG2/5-FU in nude mice. KGM may be a promising agent against the resistance of $\mathrm{HepG} 2 / 5-\mathrm{FU}$ cells to 5-FU by suppressing AKT signaling and increasing p53 expression.

\section{Introduction}

Liver cancer, including hepatocellular carcinoma (HCC), is a common and severe type of cancer worldwide (1). HCC is characterized by a high malignant degree, infiltration, metastasis and congenital drug resistance (2). Epidemiological evidence has demonstrated that there are $\sim 1$ million malignant tumor cases of HCC in the world each year with a mortality rate of $\sim 40 \%$ (3). Thus, it is necessary to explore the pathogenic mechanisms of liver cancer and to improve therapeutic regimens for patients with liver cancer.

As a common chemotherapy drug, 5-fluorouracil (5-FU) triggers apoptosis by inhibiting the thymidylic acid synthetase activity and by binding to DNA and RNA sequences (4). It has been reported that the 5 -year survival rate of advanced HCC is $\leq 10 \%$ in the USA in 2015 (5), whereas 5-FU-mediated adjuvant chemotherapy effectively reduces the mortality rates of patients with liver cancer (6). However, 5-FU-induced multi-drug resistance (MDR) often occurs in the treatment of cancer, such as HCC and colorectal cancer (7-9). Recently, MDR has been the main obstacle in chemotherapy resulting in recurrence and metastasis of cancers $(10,11)$. Thus, it is essential to find safe and effective drugs for reversing MDR.

Plants used in traditional Chinese medicine (TCM) exhibit low cytotoxicity and antitumor activity; thus, they may be useful in clinical application for cancer treatment and prevention (12). Konjac glucomannan (KGM) is extracted from Amorphophallus konjac K. Koch, which is a TCM plant. The products of this plant are listed as health foods by the World Health Organization $(13,14)$. KGM is used for obesity treatment, improving lipid metabolism, laxative, antidiabetic and anti-inflammatory effects (15). For example, KGM improves the metabolic control as determined by 
glycaemia, lipidemia and blood pressure in patients with high-risk type-2 diabetes, suggesting that KGM may be used as an alternative therapy for type-2 diabetes mellitus or reduction of blood glucose (16). KGM has also been reported to efficiently inhibit high fat diet-induced obesity in mice by attenuating insulin resistance, liver injury and inflammation, enhancing the antioxidant defense system and modulating the secretion of adipocytokines and adipogenesis-associated proteins (17). Additionally, KGM may potentially decrease the high fat-induced risk of colon carcinogenesis (18). In addition, KGM is commonly used in Asia to treat patients with chronic hepatitis (19) and is a potential compound against liver cancer (20). KGM significantly reduces the viability of HepG 2 cells and induces apoptosis-associated morphological changes (20). KGM also upregulates Bax and downregulates BCL-2 expression, indicating that the inhibitory activity of KGM on HepG2 cells is influenced by BCL-2/Bax signaling (20). Thus, KGM may be a promising drug for treatment of cancer, including HCC.

The present study aimed to investigate the reversal effects of KGM on the resistance of HepG2/5-FU cells to 5-FU in vivo and in vitro and to explore the potential mechanisms of KGM in anti-drug resistance.

\section{Materials and methods}

Cell culture. HepG2 and HepG2/5-FU cells were purchased from the Cell Conservation Center of Xiangya Medicine College, Hunan University (Hunan, China) and they were bought from American Type Culture Collection (ATCC, cat. no. ATCC $\left.{ }^{\circledR} \mathrm{HB}-8065\right)$. The cells were cultured in RPMI-1640 medium (Thermo Fisher Scientific, Inc.) containing $10 \%$ fetal bovine serum (cat. no. 16000-044, Gibco; Thermo Fisher Scientific, Inc.). The cells were seeded in 6-, 12- or 24-well plates, diluted to the final concentration of $5.0 \times 10^{5}$ cells $/ \mathrm{ml}$ and incubated at $37^{\circ} \mathrm{C}$ in a humidified incubator with an atmosphere of $5 \% \mathrm{CO}_{2}$ under aseptic conditions.

Cell viability assay. KGM was purchased from Career Henan Chemical Co. (cat. no. 37220-17-0; https://www.chemicalbook.com/ProductDetail_EN_450429.htm), and its purity was 99\%; 5-FU was purchased from Sigma Aldrich; Merck KGaA (cat. no. F6627-1G). 5-FU and KGM were diluted in DMSO and water, respectively.

Cell viability or proliferation was determined using an MTT assay. The cells (HepG2 or HepG2/5-FU) were seeded in 96-well plates at a density of $1.0 \times 10^{4}$ cells/well in $0.1 \mathrm{ml}$ RPMI-1640 medium and were exposed to increasing concentrations of 5-FU $(0.001,0.005,0.020,0.080,0.320,1.280$, $2.560,5,10,20,40,80$ or $160 \mu \mathrm{M})$ or $\operatorname{KGM}(0,2,4,8,10,100$ or $1,000 \mu \mathrm{g} / \mathrm{ml}$ ) for $24 \mathrm{~h}$.

MTT (cat. no. 57360-69-7; Sigma-Aldrich; Merck KGaA) was dissolved in DMSO to $5 \mathrm{mg} / \mathrm{ml}$; the cells were incubated with MTT for $4 \mathrm{~h}$ at $37^{\circ} \mathrm{C}$. The absorbance of the samples was measured using a microtiter plate reader at $490 \mathrm{~nm}$.

To investigate the reversal effects of KGM on the viability of HepG2/5-FU cells, the cells were preincubated with KGM $(2$ or $6 \mu \mathrm{g} / \mathrm{ml})$ and 5 -FU $(0.5 \mu \mathrm{M})$ for $24 \mathrm{~h}$ at $37^{\circ} \mathrm{C}$. The absorbance of the samples at $490 \mathrm{~nm}$ was determined by MTT assay as described above.
Apoptosis analysis by flow cytometry. Apoptosis was determined using Annexin V-fluorescein isothiocyanate (FITC)/propidium iodide (PI) staining. HepG2/5-FU cells were seeded in 96-well plates at a density of 5.0x10 cells/well. The cells were treated with 2 or $6 \mu \mathrm{g} / \mathrm{ml} \mathrm{KGM}$ for $24 \mathrm{~h}$ at $37^{\circ} \mathrm{C}$ in the presence of 5-FU. Subsequently, the cells were stained using an Annexin V-FITC/PI Apoptosis Detection kit (Beyotime Institute of Biotechnology) according to the manufacturer's instructions. The cells were analyzed using a BD FACScan flow cytometer (Becton, Dickinson and Company) and CellQuest acquisition and analysis software v.3.0 (Becton, Dickinson and Company). Early, late or early + late apoptosis was assessed and the early apoptotic cells were stained by Annexin V-FITC and the late apoptotic cells were stained by both Annexin V-FITC and PI.

Western blot analysis. The cells (HepG2 or HepG2/5-FU) were lysed in RIPA Buffer (Beyotime Institute of Biotechnology), and protein concentration was measured by bicinchoninic acid assay (Beyotime Institute of Biotechnology). Total protein $(50 \mu \mathrm{g})$ was resolved using 10\% SDS-PAGE, electro-transferred to polyvinylidene fluoride (PVDF) membranes (Beyotime Institute of Biotechnology) and blocked with 5\% non-fat dry milk in Tris-buffered saline, $\mathrm{pH} 7.5$ for $30 \mathrm{~min}$ at the room temperature. The PVDF membranes were incubated with primary antibodies against MDR1 (1:1,000; cat. no. 13978; Cell Signaling Technology Inc.); anti-P-gp (1:1,000; cat. no. ab170904; Abcam); Cyclin A1 (1:1,000; cat. no. 4656; Cell Signaling Technology Inc.); anti-cyclin B1 (1:1,000; cat. no. 4138; Cell Signaling Technology Inc.); CDK2 (1:1,000; cat. no. 2546; Cell Signaling Technology Inc.); Bcl-2 (1:1,000 dilution; cat. no. 4223; Cell Signaling Technology Inc.); Bax (1:1,000 dilution; cat. no. 14796; Cell Signaling Technology Inc.); GAPDH (1:1,000; cat. no. MB001; Bioworld, Technology Inc.); cleaved caspase-3 (1:1,000; cat. no. P42574; Bioworld Technology Inc.); p53 (1:1,000; cat. no. 9282; Cell Signaling Technology Inc.); E-cadherin (1:1,000; cat. no. 14472; Cell Signaling Technology Inc.); N-cadherin (1:1,000; cat. no. 13116; Cell Signaling Technology Inc.); AKT (1:1,000; cat. no. 4685; Cell Signaling Technology Inc.) and p-AKT (1:1,000 dilution; cat. no. 9611; Cell Signaling Technology Inc.) for $5 \mathrm{~h}$ at room temperature and the membranes were washed with PBST (Tween-20-containing phosphate-buffered saline) and incubated with horseradish peroxidase (HRP)-conjugated mouse or rabbit IgG secondary antibodies anti-HRP IgG (1:5,000; cat. no. 7074; Cell Signaling Technology Inc.) and anti-HRP IgG (1:5,000; cat. no. 7076; Cell Signaling Technology Inc.) for $1 \mathrm{~h}$ at $37^{\circ} \mathrm{C}$. Protein bands were detected by an enhanced chemiluminescence kit (Invitrogen; Thermo Fisher Scientific, Inc.) and quantified using ImageJ v.1.8.0 software (National Institutes of Health).

Reverse transcription-quantitative PCR (RT-qPCR). Total RNA was extracted from the cells (HepG2 or HepG2/5-FU) with TRIzol ${ }^{\circledR}$ reagent (Sangon Biotech Co., Ltd.,), and cDNA synthesis was performed using the PrimeScript II $1^{\text {st }}$ Strand cDNA Synthesis kit (Takara Bio, Inc.) according to the manufacturer's instructions. QPCR was performed with a SYBR ${ }^{\circledR}$ Green PCR system (Takara Bio, Inc.) in an ABI 7500 thermal cycler (Thermo Fisher Scientific, Inc.), and the thermocycling 
A

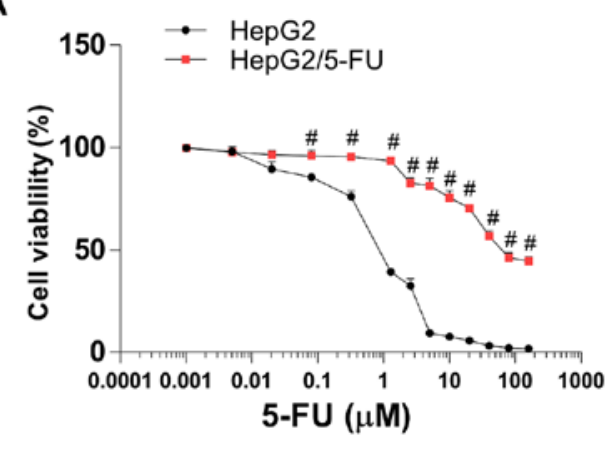

B

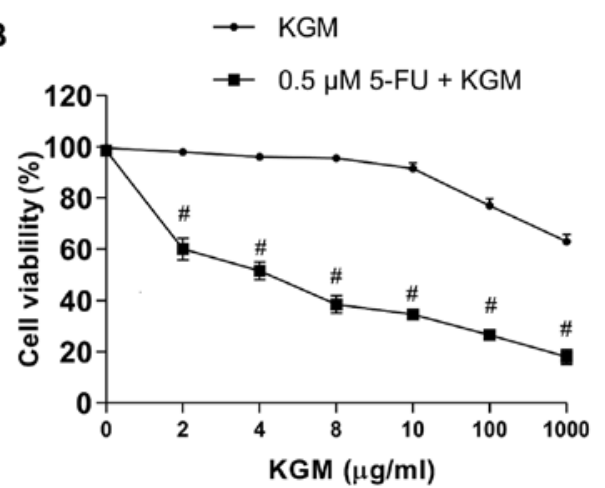

Figure 1. Effects of 5-FU and KGM on the viability of liver cancer cells. (A) $\mathrm{IC}_{50}$ values for 5-FU were $1.03 \mu \mathrm{M}$ in HepG2 and $60.02 \mu \mathrm{M}$ in HepG2/5-FU cells. (B) $\mathrm{IC}_{50}$ value for KGM was $1,500.41 \mu \mathrm{g} / \mathrm{ml}$ in HepG2/5-FU cells. ${ }^{*} \mathrm{P}<0.01$. 5-FU, 5-fluorouracil; KGM, konjac glucomannan.

conditions were as follows: $94^{\circ} \mathrm{C}$ for $5 \mathrm{~min}$; followed by 35 cycles of $94^{\circ} \mathrm{C}$ for $30 \mathrm{sec}, 58^{\circ} \mathrm{C}$ for $30 \mathrm{sec}$ and $72^{\circ} \mathrm{C}$ for $15 \mathrm{sec}$. The primers used were as follows: GAPDH forward, 5'-GCA GTGGCAAAGTGGAGATT-3' and reverse, 5'-TGAAGTCG CAGGAGACAACC-3'; MDR1 forward, 5'-TCACTTCAGTTA CCCATCTCG-3' and reverse, 5'-CACCAATGATTTCCC GTAG-3'; P-gp forward, 5'-ACTTGCAAGGGGACCAG AGA-3' and reverse, 5'-CCTTCAAGATCCATTCCGACC-3'; cyclin A forward, 5'-TCCATGTCAGTGCTGAGAGGC-3' and reverse, 5'-GAAGGTCCATGAGACAAGGC-3'; cyclin B1 forward, 5'-ATGCAGCACCTGGCTAAGAA-3' and reverse, 5'-TTACACCTTTGCCACAGCCT-3'; CDK2 forward, 5'-CTT TGCTGAGATGGTGACTCG-3' and reverse, 5'-TCATCCAG GGGAGGTACAACT-3'; and caspase-3 forward, 5'-TGCATAC TCCACAGCACCTG-3' and reverse, 5'-TCTGTTGCCACCTT TCGGTT-3'. RT-qPCR for each sample was performed in duplicate. The fold-changes were calculated by relative quantification $\left(2^{-\Delta \Delta C q}\right)(21)$. GAPDH was used as an internal control.

Tumor growth. BALB/c male nude mice (4-week-old) were purchased from the Model Animal Research Center of Nanjing University (Nanjing, China) and divided into 2 mice/group. All animal experiments were performed in accordance with the relevant guidelines of the Institutional Animal Care and Use Committee of Nanjing Medical University (approval number, SYXK 2015-0015). HepG2/5-FU cells (150 $\mu 1$, $4.0 \times 10^{6}$ cells) were injected subcutaneously into the right flank of athymic mice. The mice were housed in an isolated, clean, air-conditioned room at $24-26^{\circ} \mathrm{C}$ and a relative humidity of $\sim 50 \%$ with a $12 / 12$-h light/dark cycle and they had free access to food and water. The tumors were inspected every other day. Drug treatment was started when the tumor volume reached $40-50 \mathrm{~mm}^{3}(22)$. The mice were randomly divided into two groups 5 -FU $(2 \mathrm{mg} / \mathrm{kg})$ alone and 5 -FU $(2 \mathrm{mg} / \mathrm{kg})$ plus KGM $(20 \mathrm{mg} / \mathrm{kg})$ groups with two mice in each group. The drugs were administered every 2 days i.p. The tumor growth was determined every other day, and the tumor volume was calculated using the following formula: Volume $=$ (longest diameter $\mathrm{x}$ shortest diameter2) / 2 (22). On day 13, the tumor-bearing mice were sacrificed using the cervical dislocation method and the tumors were weighed.

Statistical analysis. The data are presented as the mean \pm standard deviation. All assays were performed as three independent experiments. Data were analyzed using Student's t-test or one-way ANOVA followed by Tukey's honestly significant difference test using SPSS 17.0 software (SPSS, Inc.). P<0.05 was considered to indicate a statistically significant difference.

\section{Results}

Effects of 5-FU and KGM on the viability of HepG2 and HepG2/5-FU cells. MTT assays were performed to measure the effects of 5-FU and KGM on the viability of liver cancer cells. The results demonstrated that 5-FU exhibited cytotoxic activity on the HepG2 and HepG2/5-FU cells with 50\% inhibitory concentration $\left(\mathrm{IC}_{50}\right)$ values of 1.03 and $60.02 \mu \mathrm{M}$, respectively (Fig. 1A). By contrast, the $\mathrm{IC}_{50}$ of KGM was 1,500.41 $\mu \mathrm{g} / \mathrm{ml}$ in HepG2 cells (Fig. 1B). Thus, 5-FU exhibited different inhibition in drug-sensitive and MDR cancer cells. In addition, 5-FU exhibited no effects on the HepG2/5-FU cell viability at $\leq 0.6 \mu \mathrm{M}$ (Fig. 1A), and KGM exhibited no cytotoxic activity on HepG2/5-FU cells at $\leq 8 \mu \mathrm{g} / \mathrm{ml}$ (Fig. 1B). Thus, to retain the 5-FU-resistant properties of HepG2/5-FU, the cells were cultured in medium containing $0.2 \mu \mathrm{M} 5$-FU.

KGM potentiates 5-FU-induced cytotoxicity and inhibits $P$-gp and MDR expression in HepG2/5-FU cells. To investigate the reversal effects of KGM on HepG2/5-FU cells, the cells were incubated with $0.5 \mu \mathrm{M} 5$-FU and/or 2 or $6 \mu \mathrm{g} / \mathrm{ml}$ KGM for $24 \mathrm{~h}$. The results demonstrated that $0.5 \mu \mathrm{M} 5-\mathrm{FU}$ exhibited no cytotoxic activity on HepG2/5-FU cells (Fig. 1A), and that 2 or $6 \mu \mathrm{g} / \mathrm{ml} \mathrm{KGM}$ also exhibited no cytotoxicity to this drug-resistant cell line (Figs. 1B and 2A). However, in the presence of $0.5 \mu \mathrm{M} 5-\mathrm{FU}, 2$ and $6 \mu \mathrm{g} / \mathrm{ml} \mathrm{KGM}$ significantly decreased HepG2/5-FU cell viability (Figs. 1B and 2A). In addition, the mRNA and protein levels of P-gp and MDR were significantly downregulated by KGM in the presence of $0.5 \mu \mathrm{M} 5$-FU compared with 5-FU or KGM treatment alone (Fig. 2B-D).

KGM suppresses the cell cycle and increases apoptosis in HepG2/5-FU cells. To investigate the effects of KGM on HepG2/5-FU cell proliferation, the expression levels of the cell cycle-related genes cyclin A, cyclin B1 and CDK2 were determined. The results demonstrated that no significant differences were observed between the protein or mRNA levels of cyclin A, cyclin B1 and CDK2 in HepG2/5-FU cells 
A

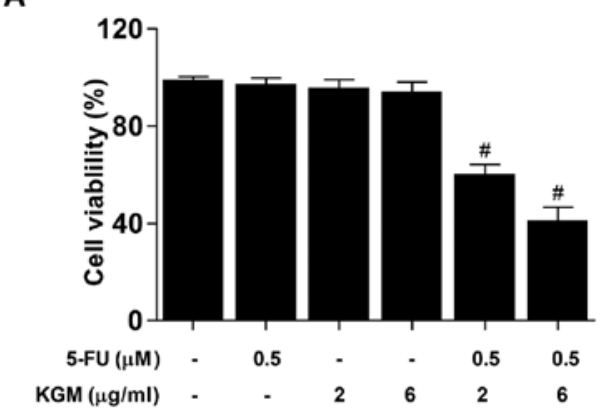

C

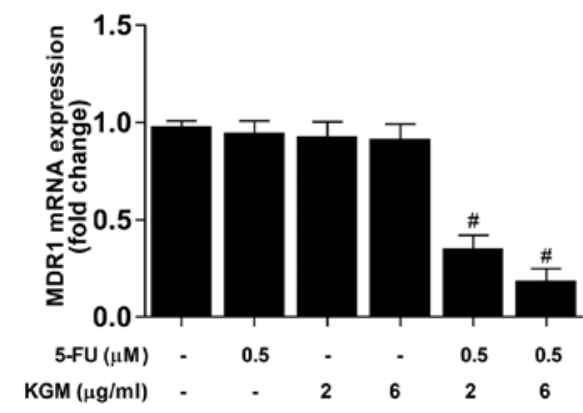

B

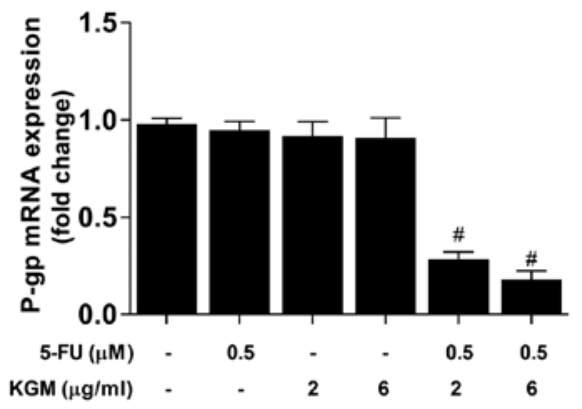

D

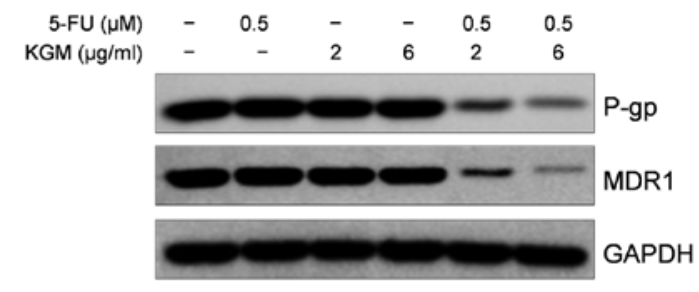

Figure 2. KGM attenuates the drug resistance of HepG2/5-FU cells. (A) HepG2/5-FU cells were incubated with $0.5 \mu \mathrm{M} 5$-FU and 2 or $6 \mu \mathrm{g} / \mathrm{ml} \mathrm{KGM}$ for $24 \mathrm{~h}$, and cell viability was assessed. (B and C) The mRNA expression of (B) P-gp and (C) MDR was analyzed by quantitative PCR. (D) The protein expression of P-gp and MDR was analyzed by western blotting. $\mathrm{n}=3 .{ }^{*} \mathrm{P}<0.01$ vs. $0.5 \mu \mathrm{M}$ 5-FU group. 5-FU, 5-fluorouracil; KGM, konjac glucomannan; P-gp, P-glycoprotein; MDR, multi-drug resistance.

following incubation with $0.5 \mu \mathrm{M} 5$-FU or $2 \mu \mathrm{g} / \mathrm{ml} \mathrm{KGM}$ alone and the control groups. By contrast, increasing concentrations of $\mathrm{KGM}$ in the presence of $0.5 \mu \mathrm{M} 5$-FU significantly reduced the protein and mRNA levels of cyclin A, cyclin B1 and CDK2 in HepG2/5-FU compared KGM treatment alone (Fig. 3A-D).

The expression of the proapoptotic gene caspase-3 was upregulated in HepG2/5-FU cells after KGM treatment in the presence of $0.5 \mu \mathrm{M} 5-\mathrm{FU}$ compared with 5-FU or KGM treatment alone (Fig. 3E). Additionally, the protein levels of the antiapoptotic gene BCL-2 level were reduced, whereas the protein levels of the proapoptotic genes Bax and caspase-3 were increased after KGM treatment in the presence of $0.5 \mu \mathrm{M}$ 5-FU in HepG2/5-FU cells compared with 5-FU or KGM treatment alone (Fig. 3F).

KGM also significantly promoted HepG2/5-FU apoptosis; KGM increased the apoptotic rate $(1.85 \pm 0.21)$ in cells treated with $0.5 \mu \mathrm{M} 5-\mathrm{FU}$ to $5.06 \pm 0.62$ and $26.91 \pm 1.73 \%$ in cells treated with $0.5 \mu \mathrm{M} 5-\mathrm{FU}$ and 2 or $6 \mu \mathrm{g} / \mathrm{ml} \mathrm{KGM}$, respectively (Fig. 3G and H).

$K G M$ reverses the resistance of $H e p G 2 / 5-F U$ cells to 5-FU in a mouse xenograft model by inhibiting 53 expression and AKT phosphorylation. To explore the potential mechanisms of KGM in reversing effects of MDR, p53 expression and AKT phosphorylation in KGM-incubated HepG2/5-FU cells was investigated. The results demonstrated that KGM significantly upregulated p53 and E-cadherin and decreased phosphorylated AKT and N-cadherin expression levels in HepG2/5-FU cells in the presence of 5-FU (Fig. 4A).

The reversal effects of KGM on the resistance of HepG2/5-FU cells to 5-FU were also investigated in vivo. The results demonstrated that $\mathrm{KGM}$ inhibited the HepG2/5-FU tumor growth in vivo (Fig. 4B); in the control group, the volume of tumors 13 days after 5-FU-treatment were 4 .69-fold higher compared with those at the start of treatment, whereas the volume of tumors 13 days after KGM and 5-FU treatment were $<1.94$-fold higher compared with those at the start of treatment (Fig. 4C). In addition, the weight of the tumors was significantly lower in the KGM-treated group compared with that in the control group (Fig. 4D).

\section{Discussion}

KGM has been used for its antiobesity, lipid metabolism-improving, laxative, antidiabetic and anti-inflammatory effects (15). KGM has also been reported to attenuate colon carcinogenesis and liver cancer $(18,20)$. The present study investigated the reversal effects of KGM on the resistance of HepG2/5-FU cells to 5-FU in vivo and in vitro, and explored the potential mechanisms of KGM in MDR. The present study demonstrated that 5-FU exhibited no cytotoxic activity on HepG2/5-FU cells at $\leq 1 \mu \mathrm{M}$, and KGM exhibited no cytotoxic activity HepG2/5-FU cells at the concentration of $\leq 8 \mu \mathrm{g} / \mathrm{ml}$. The present study demonstrated that KGM plus 5-FU attenuated the drug resistance of HepG2/5-FU cells by inhibiting HepG2/5-FU proliferation and increasing HepG2/5-FU apoptosis. In addition, KGM significantly downregulated the expression of cyclin A, cyclin B1, CDK2, and BCL-2, and upregulated the expression of Bax and cleaved caspase-3. KGM also increased the p53 expression, inhibited AKT phosphorylation and reversed the MDR of HepG2/5-FU cells in vivo resulting in suppression of tumor growth.

5-FU remains a commonly used chemotherapeutic drug in cancer treatment and clinical studies (23). The antineoplastic 
A

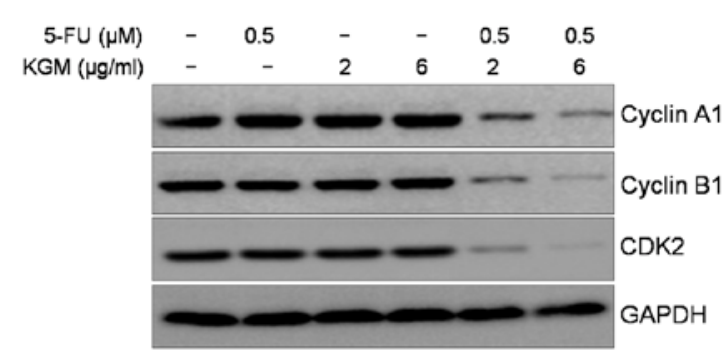

C

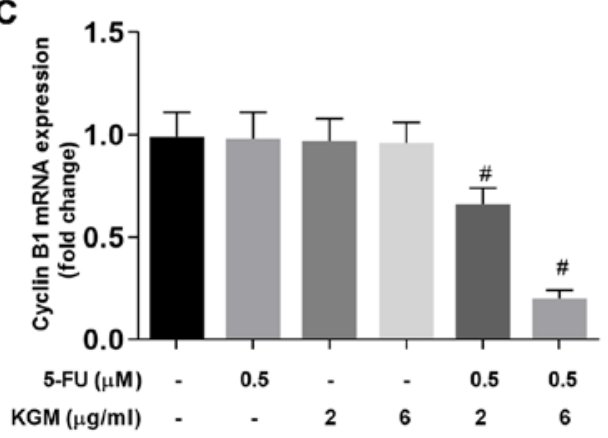

E

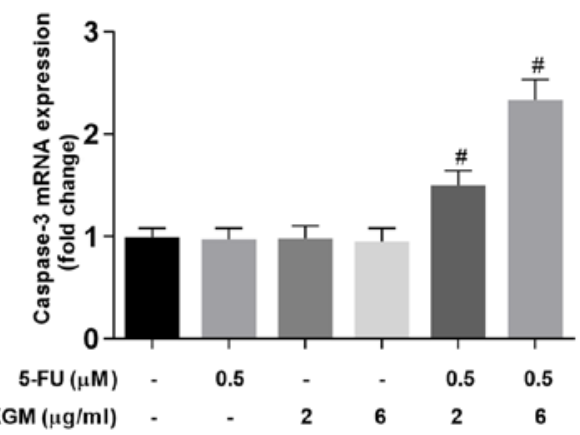

G

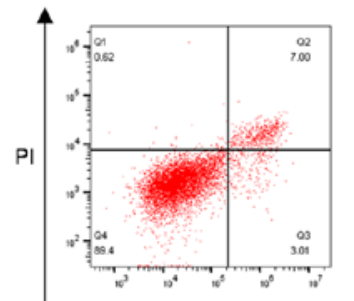

$5-\mathrm{FU}(\mu \mathrm{M}) \quad 0.5$ KGM ( $\mu \mathrm{g} / \mathrm{ml})$

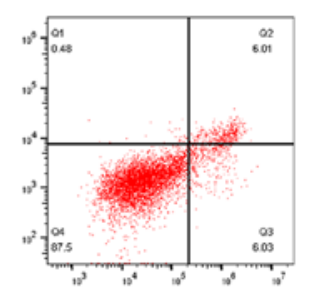

Annexin V-FITC

0.5

2
B



D

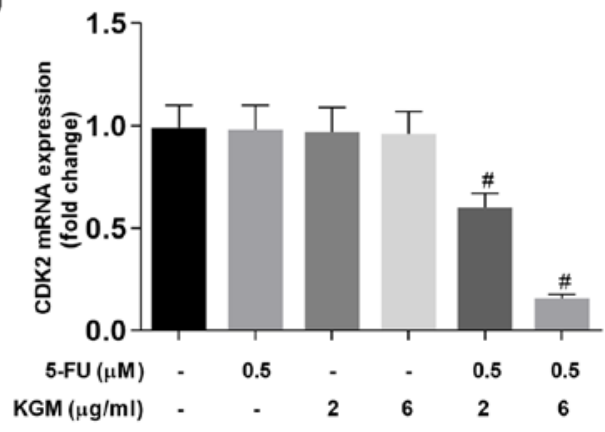

$\mathbf{F}$
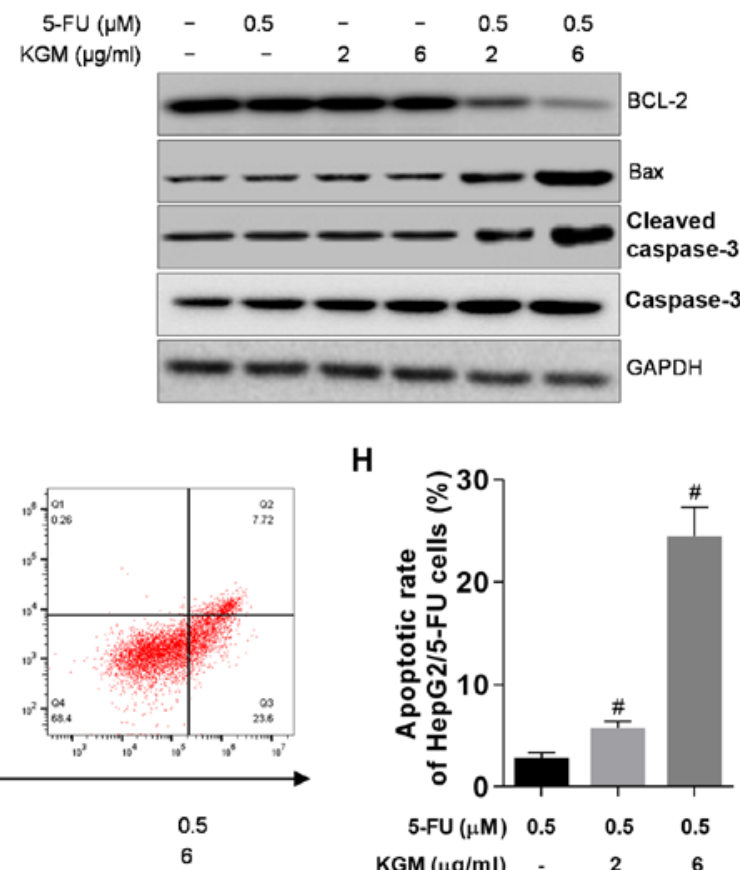

H



Figure 3. KGM inhibits HepG2/5-FU cell proliferation and promotes apoptosis. HepG2/5-FU cells were treated with $0.5 \mu \mathrm{M} 5-\mathrm{FU}$ and $2 \mu \mathrm{g} / \mathrm{ml}$ or $6 \mu \mathrm{g} / \mathrm{ml} \mathrm{KGM}$ for $24 \mathrm{~h}$. (A) The effects of KGM on cell proliferation-related gene expression (cyclin A, cyclin B1 and CDK2) were determined by western blotting. (B-E) The effects of KGM on (B) cyclin A, (C) cyclin B1, (D) CDK2 and (E) caspase-3 mRNA levels were determined by reverse transcription-quantitative PCR. (F) The effects of KGM on apoptosis-related protein (BCL-2, Bax and cleaved caspase-3) expression were demonstrated by western blotting. (G and H) The apoptotic rate of HepG2/5-FU cells was analyzed by Annexin V-FITC/propidium iodide staining. $\mathrm{n}=3 .{ }^{~} \mathrm{P}<0.01$ vs. $0.5 \mu \mathrm{M}$ 5-FU group. 5-FU fluorouracil; KGM, konjac glucomannan; CDK2, cyclin-dependent kinase 2.

efficacy of 5-FU is attributed to its ability to increase DNA damage, which results in cell cycle arrest and apoptosis (24). However, the clinical efficacy of 5-FU decreases due to the drug resistance of cancer cells (24). Thus, further studies are necessary for overcoming the drug resistance of cancer cells leading to the increasing potency of cancer therapy. In the present study, the 5-FU $\mathrm{IC}_{50}$ values were significantly higher in HepG2/5-FU cells compared with those in HepG2 cells, suggesting that HepG $2 / 5-\mathrm{FU}$ is a 5-FU-resistant cell line. In addition, increasing concentrations of KGM significantly attenuated the resistance of HepG2/5-FU cells to $5-\mathrm{FU}$ by downregulating the expression of $\mathrm{P}-\mathrm{gp}$ and MDR1 protein, 
A

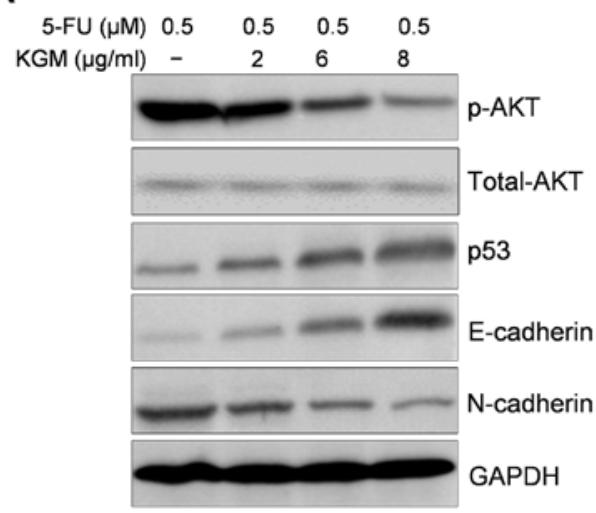

C

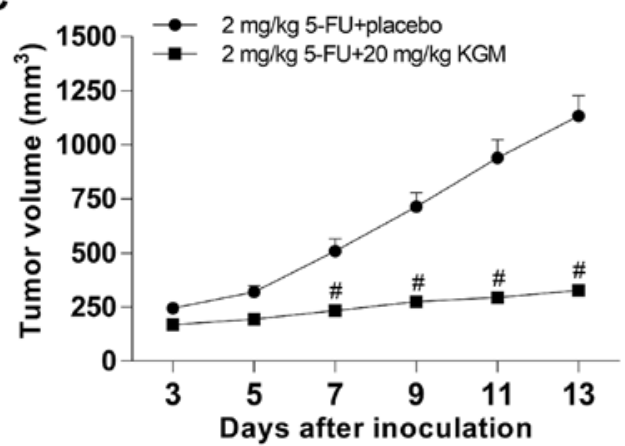

B

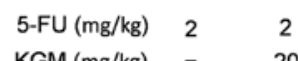

$\mathrm{KGM}(\mathrm{mg} / \mathrm{kg}) \quad-\quad 20$



D

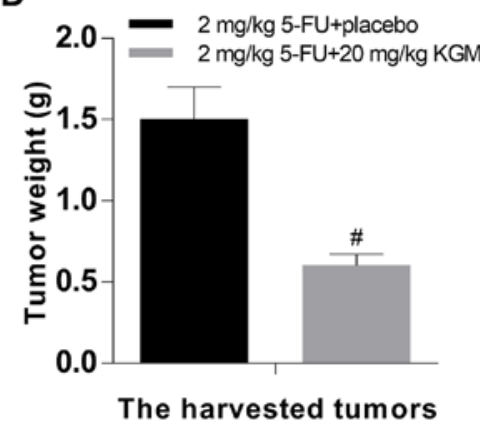

Figure 4. Effects of KGM on in vivo HepG2/5-FU tumor growth. (A) Effects of KGM on the multi-drug resistance-associated signaling determined by western blotting. (B) Images of the harvested tumors. (C) Tumor volume and (D) weight, $\mathrm{n}=2,{ }^{*} \mathrm{P}<0.01 .5$-FU fluorouracil; KGM, konjac glucomannan.

which serve an important role in 5-FU resistance (25). The present study also investigated the effects of KGM on the cell cycle and apoptosis of HepG2/5-FU cells; co-treatment with KGM and 5-FU significantly downregulated the positive regulators of cell proliferation including cyclin A, cyclin B1 and CDK2 at the protein and mRNA level, suggesting that KGM may suppress HepG2/5-FU cell proliferation. In addition, $\mathrm{KGM}+5-\mathrm{FU}$ increased the expression of the apoptosis-promoting proteins Bax and cleaved-caspase-3, decreased the expression of the antiapoptotic protein BCL-2 and elevated apoptosis in HepG2/5-FU cells. Thus, KGM may reverse 5-FU resistance in HepG2/5-FU cells by suppressing cell proliferation and enhancing apoptosis of these cells.

AKT signaling is involved in the development of MDR of cancers (26-29). For example, inhibition of AKT overcomes 5-FU resistance in SNU-C5/5-FU cells (30). Activated AKT promotes Wnt/ $\beta$-catenin signaling and activates the antiapoptotic protein mdm 2 resulting in the development of cancer, such as ovarian and prostate cancer $(31,32)$. Similarly, AKT activation positively regulates the NF- $\kappa \mathrm{B}$ pathway, enhancing cancer cell survival and resistance to apoptosis (32). Timosaponin A-III reverses MDR in human chronic myelogenous leukemia K562/ADM cells by downregulating MDR1 and multidrug resistance associated protein 1 expression and inhibiting the PI3K/AKT pathway (28). Activation of the PI3K/AKT/Snail pathway contributes to the epithelial-mesenchymal transition-induced resistance to sorafenib in HCC cells (29). AKT signaling is involved in Annexin A2-mediated MDR in gastric cancer (27). These findings suggest that the AKT pathway serves an essential role in the MDR of cancer cells. The present study demonstrated that AKT signaling was involved in MDR of HepG2/5-FU cells, and co-treatment with $\mathrm{KGM}$ and 5-FU significantly reversed the MDR of HepG2/5-FU by inactivating AKT. Previous studies have reported that the tumor suppressor gene p53 participates in chemotherapy resistance and cancer progression $(33,34)$. The present study observed that co-treatment with KGM and 5-FU increased p53 expression compared with 5-FU alone, suggesting that p53 may be involved in the reversal effects exhibited by KGM to 5 -FU resistance in HepG2/5-FU cells. Taken together, the results of the present study demonstrated the beneficial activity of KGM in the MDR of HepG2/5-FU cells by suppressing AKT signaling and elevating p53 expression.

In conclusion, KGM reversed the MDR of HepG2/5-FU cells in vitro and in vivo, inhibited the HepG2/5-FU cell proliferation and increased apoptosis. In addition, KGM plus 5-FU significantly repressed AKT signaling and promoted p53 expression. Additionally, KGM inhibited HepG2/FU cell proliferation in vivo, resulting in the suppression of tumor growth. Thus, KGM may be a promising drug for anti-MDR in clinical treatment.

\section{Acknowledgements}

The authors would like to thank Professor Zhijian Pan (the Affiliated Hospital of Hangzhou Normal University, Hangzhou, China) for technical assistance. 


\section{Funding}

This study was supported by the Science and Technology Project of Traditional Chinese Medicine Administration Bureau of Zhejiang Province (grant no. 2017A101).

\section{Availability of data and materials}

The datasets used during the present study are available from the corresponding author on reasonable request.

\section{Authors' contributions}

YX conceived and designed the experiments. BC, XX, KZ, LL and $Y Y$ performed the experiments and analyzed the data. $Y Y$ and $\mathrm{BC}$ drafted the manuscript. All authors read and approved the final manuscript.

\section{Ethics approval and consent to participate}

All animal experiments were performed in accordance with the relevant guidelines of the Institutional Animal Care and Use Committee of Nanjing Medical University (approval no. SYXK 2015-0015).

\section{Patient consent for publication}

Not applicable.

\section{Competing interests}

The authors declare that they have no competing interests.

\section{References}

1. Finn RS, Zhu AX, Farah W, Almasri J, Zaiem F, Prokop LJ, Murad MH and Mohammed K: Therapies for advanced stage hepatocellular carcinoma with macrovascular invasion or metastatic disease: A systematic review and meta-analysis Hepatology 67: 422-435, 2018.

2. Singh AK, Kumar R and Pandey AK: Hepatocellular Carcinoma: Causes, Mechanism of Progression and Biomarkers. Curr Chem Genomics Transl Med 12: 9-26, 2018.

3. Wang Y, Luo Q, Li Y, Deng S, Li X and Wei S: A systematic assessment of the quality of systematic reviews/meta-analyses in radiofrequency ablation versus hepatic resection for small hepatocellular carcinoma. J Evid Based Med 7: 103-120, 2014.

4. Hirashima Y and Shirao K: Predicting drug efficacy-fluorinated pyrimidines (fluorouracil, S-1 and capecitabine)]. Gan To Kagaku Ryoho 39: 1603-1607, 2012 (In Japanese).

5. Udali S, Guarini P, Moruzzi S, Ruzzenente A, Tammen SA Guglielmi A, Conci S, Pattini P, Olivieri O, Corrocher R, et al: Global DNA methylation and hydroxymethylation differ in hepatocellular carcinoma and cholangiocarcinoma and relate to survival rate. Hepatology 62: 496-504, 2015.

6. Chau I and Cunningham D: Chemotherapy in colorectal cancer: New options and new challenges. Br Med Bull 64: 159-180, 2002.

7. Li J, Duan B, Guo Y, Zhou R, Sun J, Bie B, Yang S, Huang C, Yang J and Li Z: Baicalein sensitizes hepatocellular carcinoma cells to 5-FU and Epirubicin by activating apoptosis and ameliorating P-glycoprotein activity. Biomed Pharmacother 98: 806-812, 2018.

8. Zhang N, Yin Y, Xu SJ and Chen WS: 5-Fluorouracil: Mechanisms of resistance and reversal strategies. Molecules 13: $1551-1569,2008$

9. Liu Z, Chen J, Yuan W, Ruan H, Shu Y, Ji J, Wu L, Tang Q, Zhou Z, Zhang X, et al: Nuclear Factor I/B Promotes Colorectal Cancer Cell Proliferation, Epithelial-Mesenchymal Transition and 5-fluorouracil Resistance. Cancer Sci 110: 86-98, 2019.
10. Koretz RL: Adjuvant chemotherapy increased survival in colorectal cancer patients with low recurrence risk. Annals of Internal Medicine 148: JC3-6, 2008

11. Saltz LB, Clarke S, Díaz-Rubio E, Scheithauer W, Figer A, Wong R, Koski S, Lichinitser M, Yang TS, Rivera F, et al: Bevacizumab in combination with oxaliplatin-based chemotherapy as first-line therapy in metastatic colorectal cancer: A randomized phase III study. J Clin Oncol 26: 2013-2019, 2008.

12. Qurishi Y, Hamid A, Majeed R, Hussain A, Qazi AK, Ahmed M, Zargar MA, Singh SK and Saxena AK: Interaction of natural products with cell survival and signaling pathways in the biochemical elucidation of drug targets in cancer. Future Oncol 7: 1007-1021, 2011.

13. Tester RF and Al-Ghazzewi FH: Beneficial health characteristics of native and hydrolysed konjac (Amorphophallus konjac) glucomannan. J Sci Food Agric 96: 3283-3291, 2016.

14. Chua M, Baldwin TC, Hocking TJ and Chan K: Traditional uses and potential health benefits of Amorphophallus konjac K. Koch ex N.E.Br. J Ethnopharmacol 128: 268-278, 2010.

15. Behera SS and Ray RC: Konjac glucomannan, a promising polysaccharide of Amorphophallus konjac K. Koch in health care. Int J Biol Macromol 92: 942-956, 2016.

16. Vuksan V, Jenkins DJ, Spadafora P, Sievenpiper JL, Owen R, Vidgen E, Brighenti F, Josse R, Leiter LA and Bruce-Thompson C: Konjac-mannan (glucomannan) improves glycemia and other associated risk factors for coronary heart disease in type 2 diabetes. A randomized controlled metabolic trial. Diabetes Care 22: 913-919, 1999.

17. Zhai X, Lin D, Zhao Y, Li W and Yang X: Enhanced anti-obesity effects of bacterial cellulose combined with konjac glucomannan in high-fat diet-fed C57BL/6J mice. Food Funct 9: 5260-5272, 2018.

18. Wu WT and Chen HL: Effects of konjac glucomannan on putative risk factors for colon carcinogenesis in rats fed a high-fat diet. J Agric Food Chem 59: 989-994, 2011

19. Villaverde AF, Benlloch S, Berenguer M, Miguel Rayón J, Pina R and Berenguer J: Acute hepatitis of cholestatic type possibly associated with the use of glucomannan (Amorphophalus konjac). J Hepatol 41: 1061-1062, 2004.

20. Sawai S, Mohktar MS, Safwani WKZW and Ramasamy TS: Suppression of the Viability and Proliferation of HepG2 Hepatocellular Carcinoma Cell Line by Konjac Glucomannan. Anticancer Agents Med Chem 18: 1258-1266, 2018.

21. Rajeevan MS, Ranamukhaarachchi DG, Vernon SD and Unger ER: Use of real-time quantitative PCR to validate the results of cDNA array and differential display PCR technologies. Methods 25: 443-451, 2001.

22. Fiebig HH, Berger DP, Winterhalter BR and Plowman J: In vitro and in vivo evaluation of US-NCI compounds in human tumor xenografts. Cancer Treat Rev 17: 109-117, 1990.

23. Longley DB, Harkin DP and Johnston PG: 5-fluorouracil: Mechanisms of action and clinical strategies. Nat Rev Cancer 3: 330-338, 2003.

24. Sasada S, Miyata Y, Tsutani Y, Tsuyama N, Masujima T, Hihara J and Okada M: Metabolomic analysis of dynamic response and drug resistance of gastric cancer cells to 5-fluorouracil. Oncol Rep 29: 925-931, 2013.

25. Yang HY, Zhao L, Yang Z, Zhao Q, Qiang L, Ha J, Li ZY, You QD and Guo QL: Oroxylin A reverses multi-drug resistance of human hepatoma BEL7402/5-FU cells via downregulation of P-glycoprotein expression by inhibiting NF- $\mathrm{KB}$ signaling pathway. Mol Carcinog 51: 185-195, 2012.

26. Martini M, De Santis MC, Braccini L, Gulluni F and Hirsch E: PI3K/AKT signaling pathway and cancer: An updated review. Ann Med 46: 372-383, 2014.

27. Zhang ZD, Li Y, Fan Q, Zhao B, Tan B and Zhao XF: Annexin A2 is implicated in multi-drug-resistance in gastric cancer through p38MAPK and AKT pathway. Neoplasma 61: 627-637, 2014.

28. Chen JR, Jia XH, Wang H, Yi YJ, Wang JY and Li YJ: Timosaponin A-III reverses multi-drug resistance in human chronic myelogenous leukemia K562/ADM cells via downregulation of MDR1 and MRP1 expression by inhibiting PI3K/Akt signaling pathway. Int J Oncol 48: 2063-2070, 2016.

29. Dong J, Zhai B, Sun W, Hu F, Cheng H and Xu J: Activation of phosphatidylinositol 3-kinase/AKT/snail signaling pathway contributes to epithelial-mesenchymal transition-induced multi-drug resistance to sorafenib in hepatocellular carcinoma cells. PLoS One 12: e0185088, 2017. 
30. Kim EJ, Kang GJ, Kang JI, Boo HJ, Hyun JW, Koh YS, Chang WY, Kim YR, Kwon JM, Maeng YH, et al: Over-activation of AKT signaling leading to 5-Fluorouracil resistance in SNU-C5/5-FU cells. Oncotarget 9: 19911-19928, 2018.

31. Do TV, Kubba LA, Antenos M, Rademaker AW, Sturgis CD and Woodruff TK: The role of activin A and Akt/GSK signaling in ovarian tumor biology. Endocrinology 149: 3809-3816, 2008.

32. Zhou Q, Yan B, Hu X, Li XB, Zhang J and Fang J: Luteolin inhibits invasion of prostate cancer PC3 cells through E-cadherin. Mol Cancer Ther 8: 1684-1691, 2009.

33. He L, Zhu $\mathrm{H}$, Zhou S, Wu T, Wu H, Yang $\mathrm{H}$, Mao $\mathrm{H}$, SekharKathera C, Janardhan A, Edick AM, et al: Wnt pathway is involved in 5-FU drug resistance of colorectal cancer cells. Exp Mol Med 50: 101, 2018.
34. Sui X, Kong N, Wang X, Fang Y, Hu X, Xu Y, Chen W, Wang K, Li D, Jin W, et al: JNK confers 5-fluorouracil resistance in p53-deficient and mutant p53-expressing colon cancer cells by inducing survival autophagy. Sci Rep 4: 4694, 2014.

(i)(9) This work is licensed under a Creative Commons Attribution-NonCommercial-NoDerivatives 4.0 International (CC BY-NC-ND 4.0) License. 